\title{
ANALISIS KRITIS PENALARAN PARAGRAF PADA TEKS SASTRA CERITA ANAK SD KELAS RENDAH BERJUDUL RAJA CENDOL
}

\author{
Ilham Febri Budiman \\ Pendidikan Guru Sekolah Dasar \\ Fakultas Ilmu Pendidikan \\ Universitas Negeri Semarang \\ Email: ilhamfebribudiman@students.unnes.ac.id
}

\begin{abstract}
Abstrak: Penalaran paragraf adalah logika atau nalar yang digunakan oleh penulis sehingga ide-ide yang ingin disampaikan kepada pembaca dapat tersampaikan dengan baik dan jelas. Teks sastra anak yang dijadikan sebagai sebagai bahan analisis pada penelitian ini ialah Raja Cendol karangan Suyitman. Penulisan artikel ini memiliki tiga tujuan. (1) Mengetahui paragraf yang bernalar pada cerita anak Raja Cendol. (2) Mengetahui paragraf yang tidak bernalar pada cerita anak Raja Cendol. (3) Mengetahui jenis paragraf pada teks cerita anak Raja Cendol. Paragraf yang bernalar dibedakan menjadi tiga, yakni berdasarkan penarikan simpulan, berdasarkan urutan logis dan berdasarkan sifatnya. Berdasarkan penarikan simpulan terdiri dari dua jenis, yaitu secara deduktif dan induktif. Berdasarkan urutan logis dibedakan sesuai urutan waktu dan tempat. Sedangkan berdasarkan sifatnya dibedakan menjadi lima, yakni paragraf narasi, eksposisi, argumentasi, persuasi dan deskripsi. Dari analisis pada teks cerita Raja Cendol ditemukan paragraf yang bernalar, yakni: penalaran induktif, deduktif, urutan tempat, urutan waktu, paragraf narasi, dan paragraf deskripsi. Pada teks cerita Raja Cendol juga ditemukan beberapa kesalahan seperti generalisasi yang terlalu luas dan relevansi yang salah.
\end{abstract}

Kata Kunci: Penalaran, paragraf, cerita anak, kelas rendah, Raja Cendol 


\section{Pendahuluan}

\subsection{Latar Belakang}

Dalam penulisan sebuah karya tulis, salah satu hal yang harus diperhatikan adalah paragraf. Paragraf yang baik harus memiliki nalar agar maksud dari penulis dapat tersampaikan dengan baik. Terlebih pada penulisan sebuah cerita anak, kebenaran dalam penalaran sebuah paragraf sangat penting karena minimnya tingkat pemahaman dan juga daya nalar pada anak usia dini. Sehingga akan menyulitkan mereka apabila ada kerancuan dalam paragraf. Penalaran paragraf dapat dilakukan dengan dua cara, yakni metode deduktif dan induktif.

Pada praktiknya, beberapa penulis masih melakukan kesalahan pada saat menyusun sebuah cerita anak khususnya pada bagian paragraf karena kurang memperhatikan kaidah penalaran paragraf. Sehingga menyulitkan anak SD tingkat rendah untuk memahami maksud dan tujuan dari paragraf tersebut. Kesalahan yang biasanya muncul pada cerita anak SD tingkat rendah ialah generalisasi yang terlampau luas, kerancuan analogi, dan relevansi yang salah.

Membaca merupakan salah satu elemen yang sangat penting dalam meningkatkan kemampuan dan perkembangan kognitif anak. Oleh sebab itu, bacaan yang diberikan kepada anak harus mudah dipahami anak. Salah satu cerita anak SD kelas rendah yang akan dijadikan bahan analisis ialah Raja Cendol karangan Suyitman. Analisis ini diharapkan dapat membantu pembaca agar dapat menyusun penalaran paragraf yang baik pada cerita anak yang akan dibuatnya.

\subsection{Rumusan Masalah}

1. Bagaimanakah paragraf yang bernalar pada cerita anak Raja Cendol?

2. Bagaimanakah paragraf yang tidak bernalar pada cerita anak Raja Cendol?

3. Apa saja jenis penalaran paragraf pada cerita anak Raja Cendol?

\subsection{Tujuan}

1. Mengetahui paragraf yang bernalar pada cerita anak Raja Cendol.

2. Mengetahui paragraf yang tidak bernalar pada cerita anak Raja Cendol.

3. Mengetahui jenis penalaran paragraf pada cerita anak Raja Cendol. 


\section{Kerangka Teoretis}

\subsection{Analisis}

Menurut (Sudjana, 2016:27) analisis adalah keterampilan yang kompleks berdasarkan tiga jenis keterampilan sebelumnya. Sedangkan menurut (Majid, 2013:57) analisis membagi satuan menjadi satuan-satuan yang terpisah, membagi satuan menjadi subbagian atau bagian, membedakan antara dua bagian yang identik, dan membaginya sesuai dengan perbedaan. Dikutip dari (Septiani, Arribe, \& Diansyah, 2020:131) Analisis adalah kegiatan berpikir yang digunakan untuk menjelaskan atau memecahkan masalah dari satuan terbesar hingga satuan terkecil.

\subsection{Berpikir Kritis}

Menurut Rasiman dan Kartinah (dalam Irdayanti, 2018:12) Berpikir kritis dapat dianggap sebagai kemampuan siswa untuk berpikir membandingkan dua atau lebih informasi, misalnya informasi yang diterima dari luar dengan informasi yang dia miliki. (Ernis, 2011:1) mengemukakan berpikir kritis ialah "Critical thinking is reasonable, reflective thinking that is focused on deciding what to believe or do" atau dapat diartikan dengan pemikiran masuk akal yang berfokus pada apa yang akan dilakukan.

Menurut Inch (Irdayanti, 2018:24) terdapat delapan unsur pembentuk berpikir kritis, yakni (1) masalah, (2) tujuan, (3) data-data dan fakta, (4) kerangka teoretis, (5) permulaan solusi, (6) keranga utama solusi, (7) simpulan atau hasil akhir, (8) objek yang dikaji. Dapat diketahui bahwa kemampuan berpikir kritis tidak dimiliki oleh semua orang, karena dalam penyelesainnya harus memiliki solusi yang terbaik. Kemudian juga terdapat beberapa unsur yang harus dipenuhi dalam berpikir kritis.

Menurut (Ernis, 2011:2) terdapat beberapa indikator dalam proses berpikir kritis, yaitu. (1) Pengkasilifkasian masalah secara mendasar. (2) Alasan dan argumen dalam mengambil keputusan-keputusan. (3) Menarik simpulan atas permasalahan umum. (4) Membuktikan validitasnya dengan metode klarifikasi. (5) Merumuskan dugaan sementara atau hipotesis agar mendapatkan gambaran mengenai permasalahan yang dikaji. 


\subsection{Penalaran Paragraf}

Menurut (Suladi, 2015:94) penalaran ialah proses mengamati melalui indera yang akan menghasilkan pemikiran-pemikiran dalam bentuk konsep dan definisidefinisi. Dalam prosesnya, akan diperlukan data-data yang valid untuk menghasilkan suatu rumusan atau simpulan. Simpulan yang dihasilkan memiliki dua kemungkinan, yaitu benar dan tidak benar. Dalam hal ini pembaca atau penulis lainnya boleh tidak percaya.

Menurut (Suladi, 2015:1) hakikat paragraf ialah sekumpulan kalimat dengan gagasan tunggal (sama) yang membentuk satu ide pokok. Paragraf memiliki fungsi untuk memudahkan pembaca dalam memahami topik yang dibahas karena ide pokok/ topiknya tunggal. Dalam sebuah tulisan, biasanya paragraf ditandai dengan pada sebuah tulisan yang menjorok ke dalam. Bagian yang menjorok itu merupakan awal sebuah paragraf.

Dapat disimpulkan bahwa penalaran paragraf adalah logika atau nalar yang digunakan oleh penulis sehingga ide-ide yang ingin disampaikan kepada pembaca dapat tersampaikan dengan baik dan jelas. Oleh karena itu, penalaran dalam sebuah paragraf sangat penting. Berdasarkan penalarannya, paragraf dibedakan menjadi dua yaitu paragraf yang bernalar dan paragraf yang tidak bernalar.

\subsection{Cerita Anak}

Menurut Puryanto (dalam Devianty, 2017:3) cerita anak adalah karya sastra yang secara khusus dikarang dengan memperhatikan tingkat pemahaman anak dan sesuai dengan lingkungannya. Karakteristik sastra anak menurut Lukens (dalam Devianty, 2017:4) dua hal utama yang ditawarkan ialah kesenangan dan juga pemahaman. Dalam hal ini sastra anak harus memiliki unsur amanat yang baik bagi perkembangan si anak.

Menurut Monsher (Ermadwicitawati, Sudiana, \& Sutama, 2013:5) cerita anak sebagai karya sastra diciptakan oleh penulis untuk menyampaikan pesan kepada pembaca. Pesan-pesan yang terkandung dalam mencakup banyak, termasuk pesan moral, pesan sosial, pesan politik, masalah keuangan, dan banyak lagi. Pesan ini memainkan peran yang sangat penting bagi pembaca dan kehidupan mereka. 


\subsection{Karakteristik Cerita Anak SD Kelas Rendah}

Dikutip dari (Krissandi, Febriyanto, Cahya, \& Radityo, 2018:24) karakteristik sastra anak secara umum yaitu. (1) Gaya bahasa sederhana dan langsung disesuaikan dengan usia pembaca. (2) Cerita berfokus pada plot. Jadi apa yang dilakukan dalam cerita, dan apa hasil dari plot tersebut. (3) Dilampirkan dengan gambar atau ilustrasi yang dirancang untuk memberikan informasi visual dan emosional yang tidak dapat disampaikan oleh teks itu sendiri. (4) Tokoh protagonis umumnya adalah anak atau binatang yang menunjukkan sifat dan perilaku kekanakkanakan sehingga pembaca anak dapat mengidentifikasi mereka sebagai karakter mereka.

Cerita anak pada SD Kelas Rendah memiliki beberapa karakteristik yang tak jauh berbeda dengan sastra anak secara umum, yakni; (1) Bahasa yang digunakan mudah dipahami. (2) Tema diambil dari lingkungan anak usia dini. (3) Alur yang digunakan tunggal, biasanya maju. (4) Mengandung nilai amanat yang berguna bagi anak. (5) Biasanya tidak bercerita tentang masalah percintaan. (6) Pilihan kata yang digunakan bersifat dasar ataupun umum.

\subsection{Teks Cerita Raja Cendol}

Dalam cerita ini berkisahkan anak yang di titipkan oleh seorang kesatria berkuda yang semakin lama tumbuh menjadi pemuda yang pintar membuat minuman yaitu cendol. Ia mahir membuat cendol karena sejak kecil ia diajari membuat nya, hingga pada akhirnya minuman cendol itu dikenal dan disukai oleh raja raja. Namun saat menemui salah satu raja, raja itu teringat bahwa dahulu ia menitipkan anak yaitu pemuda itu dan pada akhirnya raja itu menjelaskan siapa sebenarnya dirinya itu, dan pada akhirnya dia sebagai putra mahkota., walaupun ia mengetahui bahwa dirinya adalah putra mahkota ia senantiasa rendah hati layaknya penjual cendol. Wedang Cendol sendiri adalah minuman khas Indonesia tepatnya dari berasal dari Bandung yang terbuat dari tepung beras lalu tepung ini di olah dan di beri warna hijau yang warna itu berasal dari daun suji. 


\section{Pembahasan}

\subsection{Paragraf yang Bernalar}

Paragraf yang bernalar adalah paragraf yang dalam penyusunannya menggunakan logika atau nalar dalam menentukan kata maupun kalimat yang akan dituangkan ke dalam paragraf tersebut. Sehingga memudahkan pembaca dalam menganalogikan maksud dari penulis.

\subsubsection{Berdasarkan Simpulan}

\section{Penalaran Induktif}

Menurut Santrock (dalam Faozin, 2016:7), penalaran induktif adalah proses penalaran dari hal-hal yang sifatnya spesifik ke umum. Jadi penalaran induktif merupakan sebuah proses yang beranjak dari peristiwa khusus atau spesifik berdasarkan hasil sebuah pengamatan sehingga dapat menghasilkan sebuah kesimpulan yang bersifat umum. Dalam jenis penalaran ini terjadi sebuah proses berpikir dengan berusaha untuk menghubung-hubungkan fakta yang ada. Cara yang dapat digunakan yakni:

a) Generalisasi, suatu penalaran yang didasarkan beberapa fenomena individual yang memiliki hubungan dan kemudian diambil kesamaannya sehingga didapat sebuah kesimpulan yang bersifat general atau umum.

b) Analogi, sebuah proses penalaran diambil dari dua peristiwa khusus yang mirip, kemudian disimpulkan apakah yang berlaku untuk satu hal juga berlaku pula untuk hal yang lainnya.

c) Kausalitas, kausalitas atau hubungan sebab-akibat merupakan penyusunan paragraf berdasarkan isi sebab-akibat. Adapun polanya ialah; sebab-akibat, akibat-sebab, dan akibat-akibat.

Contoh pada cerita anak Raja Cendol:

(1) Ranu tumbuh menjadi anak yang rajin. Setiap hari Ranu membantu Pak Eku membuat cendol. Ranu bertugas mengaduk tepung beras dengan sedikit air perasan daun pandan dan suji. Setelah merata, adonan itu direbus hingga mengental. Lalu, Ranu mencetaknya menjadi butiranbutiran cendol yang menarik. (Suyitman, 2017:2) 
Pada contoh (1) dapat dikategorikan menjadi penalaran induktif karena dimulai dengan hal yang bersifat khusus yakni Ranu tumbuh menjadi anak rajin. Kemudian diterangkan hal-hal umum yang menyebabkan Ranu menjadi anak yang rajin yaitu kegiatannya membantu Pak Eku membuat cendol.

\section{Penalaran Deduktif}

Menurut Santrock (dalam Faozin, 2016:8), penalaran deduktif adalah proses penalaran dari umum ke khusus. Sehingga sangat jelas bahwa Penalaran deduktif merupakan penalaran logis dari pernyataan yang general untuk membuat kesimpulan yang bersifat khusus. Penalaran ini dapat dilakukan menggunakan metode silogisme, yakni berisi dua buah premis dan satu kesimpulan.

Contoh pada cerita anak Raja Cendol:

(2) Saat menyajikan cendol, tubuh Ranu bergetar, kakinya terasa berat untuk melangkah. Ingin sekali Ranu bersimpuh di hadapan sang Raja Seberang. Akan tetapi, apa Raja Seberang merasakan hal yang sama? Ah, beliau hanya terpaku menatap cendol. (Suyitman, 2017:5)

Pada contoh (2) dapat dikategorikan penalaran induktif karena didahului oleh hal yang bersifat umum yakni saat Ranu menyajikan cendol. Kemudian disusul dengan hal khusus yaitu kondisi Ranu saat ingin menyajikan cendol.

\subsubsection{Berdasarkan Urutan Logis}

\section{Urutan Tempat}

Paragraf berdasarkan urutan tempat yakni mengurutkan perpindahan dari suatu tempat ke tempat yang lain dengan sistem kronologis.

Contoh pada cerita anak Raja Cendol:

(3) Pak Eku dikejutkan oleh suara tangis. Dia segera mendekati sumber suara. Dilihatnya bayi laki-laki mungil itu sedang menangis. Pak Eku merasa kasihan. Dia segera pergi membawa bayi itu. Pak Eku tidak kembali ke rumah. Dia meninggalkan kampung halamannya. (Suyitman, 2017:1) 
Pada contoh (3) dapat dikategorikan berdasarkan urutan tempat karena dimulai dari bayi di balik semak yang kemudian dibawa ke rumah oleh Pak Eku. Urutan tempat pada paragraf tersebut juga bersifat kronologis atau berurutan.

\section{Urutan Waktu}

Urutan waktu pada penalaran paragraf ialah menjelaskan suatu kejadian berdasarkan urutan waktu, baik itu maju maupun mundur.

Contoh pada cerita anak Raja Cendol:

(4) Untuk memulai pencariannya, Pak Eku mengajak Ranu berjualan cendol di tanah kelahirannya, tempat dulu Ranu dititipkan. Pak Eku berharap kesatria berkuda akan kembali menemuinya. Akan tetapi, setelah setahun berjualan, kesatria itu tak kunjung datang. (Suyitman, 2017:2)

Pada contoh (4) dikategorikan dalam urutan waktu karena penalaran yang digunakan ialah secara maju atau dari masa kini ke masa depan. Dibuktikan dengan awal mula berjualan cendol hingga setahun kemudian.

\subsubsection{Berdasarkan Sifatnya}

\section{Paragraf Narasi}

Paragraf ini menceritakan suatu kejadian atau kehidupuan seseorang yang disusun secara kronologis.

Contoh pada cerita anak Raja Cendol:

(5) Ayah, kita pindah ke mana lagi?" protes Ranu. "Bukankah cendol kita selalu habis?" "Kita ke kerajaan di selatan. Di sana pemandangannya lebih asyik. Ada pantai dengan pasir putih yang indah," jawab Pak Eku berkilah. (Suyitman, 2017:2-3)

Pada contoh (5) termasuk dalam paragraf narasi karena pada paragraf tersebut menunjukan sebuah narasi antara Ranu dan Pak Eku mengenai rencana untuk pindah tempat berjualan. 


\section{Paragraf Eksposisi}

Paragraf ini berisi mengenai pemaparan, penjelasan, penyampaian, penerangan tentang suatu informasi yang aktual. Pada cerita anak Raja Cendol tidak dapat ditemukan paragraf eksposisi. Karena paragraf jenis ini umumnya terdapat pada teks nonfiksi khususnya teks eksposisi.

\section{Paragraf Argumentasi}

Paragraf ini berisi pendapat mengenai suatu permasalahan yang bertujuan untuk meyakinkan seseorang. Pada cerita anak Raja Cendol tidak dapat ditemukan paragraf argumentasi. Karena biasanya terdapat pada teks berita ataupun esai.

\section{Paragraf Persuasi}

Paragraf ini berisi pemaparan gagasan yang diikuti dengan ajakan kepada pembaca untuk ikut dalam topik yang dibahas. Pada cerita anak Raja Cendol tidak dapat ditemukan paragraf persuasi karena pada umumnya terdapat pada persuasif.

\section{Paragraf Deskripsi}

Berisi deskripsi tentang suatu hal yang bertujuan untuk memberi kesan kepada pembaca.terhadap hal tersebut.

Contoh pada cerita anak Raja Cendol:

(6) Ranu pun melampiaskan perasaan yang sejak tadi dipendamnya. Raja Barat tak mampu membendung air matanya. Begitu juga dengan semua orang yang ada di dalam istana. Semua orang larut dalam keharuan. (Suyitman, 2017:6)

Pada contoh (6) tergolong dalam paragraf deskripsi karena pada paragraf tersebut mendeskripsikan kondisi pertemuan antara Raja Barat dan Ranu saat Ranu tahu bahwa Raja Barat adalah ayah kandungnya.

\subsection{Paragraf yang Tidak Bernalar}

Paragraf yang tidak bernalar atau yang sering disebut salah nalar. Salah nalar sering terjadi dikarenakan oleh kesalahan berpikir dalam menilai suatu hal sehingga terjadi kerancuan dan perubahan maksud. 


\subsubsection{Generalisasi yang Terlampau Luas}

Generalisasi yang terlampau disebabkan oleh kurangnya data-data dan fakta yang menjadi dasar pengambilan simpulan. Kekurangan data tersebut bisa terjadi karena memang jumlah data terbatas, malas mengumpulkan bukti-bukti, atau ingin sesegera mungkin meyakinkan orang lain.

Contoh pada cerita anak Raja Cendol:

(7) Selamatkan bayi ini. Selamatkan!" kata kesatria berkuda sambil meletakkan bungkusan di balik semak. Kesatria itu menatap Pak Eku dengan iba. Belum sempat berkata, kesatria itu pergi ketika melihat pasukan berkuda berlari kencang di belakangnya. "Jangan biarkan dia lolos, " kata salah seorang penunggang kuda. (Suyitman, 2017:1)

Kesalahan pada contoh (7) ialah pada paragraf tersebut kata "kesatria berkuda" memiliki makna seluruh kstarisa berkuda. Seharusnya diganti menjadi "sosok kesatria berkuda" atau "seorang kesatria berkuda".

\subsubsection{Kerancuan Analogi}

Kerancuan analogi dapat terjadi karena penganalogian yang tidak tepat karena terdapat dua hal yang menjadi perbandingan memiliki ketidaksamaan karakter. Kesamaan yang terjadi hanya sebagian kecil atau bahkan sebuah kebetulan belaka. Pada cerita anak Raja Cendol tidak terdapat kerancuan analogi.

\subsubsection{Kekeliruan Kausalitas}

Kausalitas yang keliru dapat terjadi akibat kekeliruan mengidentifikasi gejala atau persoalan yang menjadi sebuah hubungan sebab-akibat. Kekeliruan mengidentifikasi sebab atau akibat akan menyebabkan simpulan yang diambil juga tidak tepat. Pada cerita anak Raja Cendol tidak terdapat kekeliruan kausalitas.

\subsubsection{Relevansi yang Salah}

Kesalahan ini terjadi dua buah premis tidak memiliki hubungan antara logika dengan kesimpulan. Jadi ketika sebuah pernyataan memiliki premis yang tidak relevan, maka kebenarannya perlu dipertanyakan. 
Contoh pada cerita anak Raja Cendol:

(8) Belum sempat berkata, kesatria itu pergi ketika melihat pasukan berkuda berlari kencang di belakangnya. (Suyitman, 2017:1)

Pada contoh (8) terjadi kekeliruan dimana pasukan yang sedang berkuda tetapi juga berlari. Seolah yang berlari adalah pasukan (orang) bukan kudanya. Seharusnya bisa diganti menjadi "Pasukan berkuda yang datang dengan cepat".

\subsubsection{Penyandaran Prestise Seseorang}

Salah nalar ini timbul karena penulis bergantung pada pendapat seseorang yang terkenal namun bukan seorang ahli pengetahuan. Tidak terdapat kesalahan ini pada teks Raja Cendol.

\subsection{Jenis Penalaran Paragraf pada Cerita Anak Raja Cendol}

Berdasarkan analisis kritis penalaran paragraf pada cerita anak Raja Cendol maka diperoleh hasil sebagai berikut:

Tabel 1: Analisis Penalaran Paragraf Berdasarkan Simpulan

\begin{tabular}{|c|l|c|c|}
\hline No & Jenis Paragraf & Jumlah & Persentase \\
\hline 1 & Penalaran induktif & 9 & $27 \%$ \\
\hline 2 & Penalaran deduktif & 26 & $73 \%$ \\
\hline \multicolumn{2}{r|}{ Total } & $\mathbf{3 5}$ & $\mathbf{1 0 0 \%}$ \\
\hline
\end{tabular}

Tabel 2: Analisis Penalaran Paragraf Berdasarkan Urutan Logis

\begin{tabular}{|c|l|c|c|}
\hline No & \multicolumn{1}{|c|}{ Jenis Paragraf } & Jumlah & Persentase \\
\hline 1 & Urutan tempat & 6 & $21 \%$ \\
\hline 2 & Urutan waktu & 29 & $79 \%$ \\
\hline \multicolumn{2}{|c|}{ Total } & $\mathbf{3 5}$ & $\mathbf{1 0 0 \%}$ \\
\hline
\end{tabular}


Tabel 3: Analisis Penalaran Paragraf Berdasarkan Sifatnya

\begin{tabular}{|c|l|c|c|}
\hline No & \multicolumn{1}{|c|}{ Jenis Paragraf } & Jumlah & Persentase \\
\hline 1 & Narasi & 11 & $31 \%$ \\
\hline 2 & Deskripsi & 24 & $69 \%$ \\
\hline 3 & Argumentasi & - & - \\
\hline 4 & Persuasi & - & - \\
\hline 5 & Eksposisi & - & - \\
\hline \multicolumn{2}{|c|}{ Total } & $\mathbf{3 5}$ & $\mathbf{1 0 0 \%}$ \\
\hline
\end{tabular}

Tabel 4: Analisis Salah Nalar

\begin{tabular}{|c|c|c|c|}
\hline No & Jenis Paragraf & Jumlah & Persentase \\
\hline \multirow[t]{6}{*}{1} & Salah Nalar & & \\
\hline & - Generalisasi yang luas & 1 & $3 \%$ \\
\hline & - Relevansi yang salah & 1 & $3 \%$ \\
\hline & - Kerancuan analogi & - & - \\
\hline & - Kekeliruan Kausalitas & - & - \\
\hline & - Penyandaran prestise & - & - \\
\hline 2 & Paragraf yang bernalar & 33 & $94 \%$ \\
\hline \multicolumn{2}{|r|}{ Total } & 35 & $100 \%$ \\
\hline
\end{tabular}

Dari analisis data pada cerita anak Raja Cendol, maka dapat diperoleh: (1) Jenis paragraf yang paling banyak digunakan berdasarkan simpulan adalah penalaran deduktif dibanding induktif. (2) Jenis paragraf berdasarkan urutan logis lebih banyak berdasarkan urutan waktu ketimbang urutan tempat. (3) Jenis paragraf berdasarkan sifatnya hanya terdapat dua jenis, yakni deskripsi dan narasi dengan lebih banyak deskripsi. (4) Masih terdapat salah nalar pada cerita Raja Cendol yakni generalisasi yang terlalu luas dan relevansi yang salah dengan masing-masing satu paragraf. 


\section{Penutup}

\subsection{Simpulan}

Penalaran paragraf adalah logika atau nalar yang digunakan oleh penulis sehingga ide-ide yang ingin disampaikan kepada pembaca dapat tersampaikan dengan baik dan jelas. Dari analisis di atas dapat disimpulkan bahwa pada teks cerita Raja Cendol ditemukan beberapa jenis paragraf yang bernalar, yakni: penalaran induktif, deduktif, urutan tempat, urutan waktu, paragraf narasi, dan paragraf deskripsi. Pada teks cerita Raja Cendol juga ditemukan beberapa kesalahan seperti generalisasi yang terlalu luas dan relevansi yang salah. Penalaran yang paling umum digunakan pada teks cerita Raja Cendol ialah penalaran deduktif dengan memperhatikan urutan waktu.

\subsection{Saran}

Dalam penulisan paragraf pada cerita anak sebagai karya sastra anak, hendaknya harus diperhatikan karena hal itu dapat menarik minat pembaca (anakanak). Tentunya dalam penulisan paragraf tidak berbelit-belit agar dapat dipahami anak. Selain itu, juga diperlukan penalaran dalam paragraf sebagai penyempurnaan tatanan paragraf menjadi lebih baik, sehingga pembaca yang didominasi oleh anak SD kelas rendah tidak merasa kesulitan dalam memahami maksud dari paragraf. 


\section{Daftar Pustaka}

Devianty, R. (2017). Membangun Karakter Anak Melalui Sastra. Raudhah Vol. V, 1-16. Diunduh pada 11 November 2021.

Ermadwicitawati, Sudiana, \& Sutama. (2013). Pengembangan Materi Ajar Cerita Anak yang Mengandung Pendidikan Karakter Pada Pembelajaran Membaca Cerita Anak SMP Kelas VII di Singaraja. e-Journal Program Pascasarjana Universitas Pendidikan Ganesha, 1-11. Diunduh pada 11 November 2021.

Ernis, R. (2011). The Nature of Critical Thinking : An Outline of Critical Thinking. University of Illinois, 1-8. Diunduh pada 11 November 2021.

Faozin, D. (2016). Pengaruh Brain Based Learning Terhadap Kemampuan Penalaran Matematis dan Percaya Diri Siswa SMP Cokroaminoto Banjarmangu. Repository UMP, 1-65. Diunduh pada 11 November 2021.

Irdayanti, L. S. (2018). Tingkat Kemampuan Berpikir Kritis Matematis Siswa di SMPN 1 Kedungwaru Melalui Pemberian Soal Open-Ended Materi Teorema Pythagoras Tahun Ajaran 2017/2018. Repository IAIN Tulungagung, 1-110. Diunduh pada 11 November 2021.

Krissandi, Febriyanto, Cahya, \& Radityo. (2018). Sastra Anak: Media Pembelajaran Sastra Anak. Yogyakarta: Bakul Buku Indonesia. Diunduh pada 11 November 2021.

Majid, A. (2013). Strategi Pembelajaran. Bandung: Remaja Rosdakarya. Diunduh pada 11 November 2021.

Septiani, Y., Arribe, E., \& Diansyah, R. (2020). Analisis Kualitas Layanan Sistem Informasi Akademik. Jurnal Teknologi dan Open Source Vol. 3 No. 1, 131143. Diunduh pada 11 November 2021.

Sudjana, N. (2016). Penilaian Hasil Proses Belajar Mengajar. Bandung: PT. Remaja Rosdakarya Offse. Diunduh pada 11 November 2021.

Suladi. (2015). Seri Penyuluhan Bahasa Indonesia: Paragraf. Jakarta: Pusat Pembinaan dan Pemasyarakatan. Diunduh pada 11 November 2021.

Suyitman. (2017). Cerpen dan Dongeng Minuman Nusantara. Jakarta: Badan Pengembangan dan Pembinaan Bahasa. Diunduh pada 11 November 2021.

\section{Lampiran}

Link e-book cerita anak Raja Cendol:

https://budi.kemdikbud.go.id/buku/pdf/19.\%20Isi\%20dan\%20Sampul\%20Cerp en\%20dan\%20Dongeng\%20Minuman\%20Nusantara.pdf 